\title{
Aproximación a la sintaxis y a la semántica del rito en el Libro del Amduat
}

An approach to syntax and semantics of the rite in the Book of the Amduat

Mariano Bonanno

Investigador Independiente, Argentina

mbonanno1971@gmail.com

\section{Resumen:}

El objeto de este estudio es el denominado Libro Amduat del Reino Nuevo egipcio, texto que contiene instrucciones paratextuales que parece como si fuesen representadas o que cumple aquello que describe (performatividad). Lo que aquí proponemos es continuar y complementar las conclusiones de Hays (2013:165-186) sobre las limitaciones del modelo de Van Gennep en contraposición a la sintaxis ritual como modelo de análisis a partir de estos paratextos o instrucciones. En este sentido, la idea es completar la afirmación de Hays acerca de que aquel modelo no funciona con todo el material ritual egipcio. Asimismo, la articulación entre el lenguaje y lo simbólico, serán tratados.

Palabras clave: Paratexto, Performatividad, Sintaxis, Ritos.

\section{AbStract:}

The aim of this paper is the so-called New Kingdom Book of Amduat, corpora that contain paratextual instructions that seem as if they were represented or that fulfill what they describe (performativity). What we propose here is to continue with -and complement- Hay's conclusions (2013:165-186) about the limitations of Van Gennep's analysis model starting with these paratexts or instructions. In this sense, the idea is to complement Hay's assertion according to which the model does not work with the entire Egyptian materials for ritual. Likewise, this paper presents an analysis of the articulation between language and "the symbolic".

KEYWORDS: Paratext, Permormativity, Syntax, Rites.

\section{INTRODUCCIÓN}

El artículo de Hays acerca de las metodologías para el análisis de la estructura ritual egipcia (Hays, 2013:165-186) en general y para el caso de las representaciones funerarias en particular, ha sido el punto de partida para la indagación que aquí propongo.

Lo que aquí se plantea es continuar y complementar las conclusiones de Hays sobre las limitaciones del modelo de Van Gennep (Van Gennep, 1960:15-25; Turner, 2008) en contraposición a la sintaxis ritual como modelo de análisis a partir de estos paratextos o instrucciones como dispositivos para asegurar el resultado de los rituales ${ }^{1}$.

\section{Sinopsis del modelo de VAN Gennep: Ritualidad cósmica}

El ingreso de Ra en la Duat ${ }^{2}$ y la vinculación que define su relación de contigüidad onto-teológica con Osiris, nos ocupa en esta primera parte del estudio. La cercanía ontológica derivada de la complejidad de esta figura que se auto-regenera durante las 12 horas de oscuridad, presupone una variedad de estaciones, indeterminaciones y alternancias que no puede reducirse a un proceso único. De esta manera, el paso solar 
supone un movimiento que puede asimilarse a un rite de passage dada la alternancia de estados que se complementan. De separación (cuerpo y bA como entidades separadas), transición (momento generador del paso solar) e incorporación (unión final de cuerpo y bA), es la sucesión resultante. Esta secuencia simplificada es la expresión más acabada de la singularidad funcional solar de reconversión.

El carácter cósmico de los sucesos generados a partir del decrecimiento del poder de Ra, merma (ingreso) -reconversión (tránsito)-y reconversión (salida de la Duat) concilia en cada movimiento aquellos que en un contexto individual operarían en forma autónoma.

Esto significa que la activación propuesta por el rito promueve progresiones exclusivas que directamente comprometen la regularidad cíclica universal. De este modo, las consecuencias de su incumplimiento devienen en la detención, el caos o el aniquilamiento del destinatario de los rituales.

Este rito cósmico entraña la anulación de la fenomenología que conlleva la instrumentación de cualquier acción ritual; no obstante, debemos considerar la posibilidad de un complemento terreno con aquellas acciones "automáticas" de carácter cósmico-divino.

\section{TABLA 1}

Sinopsis comparativa entre los ritos individuales y divinos

\begin{tabular}{|c|c|}
\hline $\begin{array}{l}\text { Rito funerario individual } \\
\text { (limitado) }\end{array}$ & $\begin{array}{l}\text {-activación por terceros (ritualistas) } \\
\text {-consecuencias acotadas } \\
\text {-individuación/reducción ontológica } \\
\text {-dependencia de instancias superiores } \\
\text {-interacción necesaria con lo terreno } \\
\text {-posibilidad de interrumpirla secuencia y su repetición } \\
\text {-desencadenamiento por inmanencia }\end{array}$ \\
\hline $\begin{array}{l}\text { Rito funerario divino } \\
\text { (cósmico) }\end{array}$ & $\begin{array}{l}\text {-consecuencias trascendentes e integradoras } \\
\text {-prescindencia -no excluyente- de intermediación } \\
\text { terrena } \\
\text {-conjunción/sinergia divina } \\
\text {-traslación-dispersión de los efectos regenerativos } \\
\text {-imposibilidad de interrupción por su carácter } \\
\text { cósmico-natural } \\
\text {-actos terrenos como refuerzoy complemento }\end{array}$ \\
\hline
\end{tabular}

La secuencia día-noche, su ascendencia en Ra y sus derivaciones, aplicadas al faraón en primer lugar (en el caso del Libro del Amduat) y al resto de los difuntos luego, nos plantea por un lado, un contexto ad divinum modum, es decir, prescindente de la actividad humana, y por otro, uno de índole más personal. 
TABLA 2

Correlato hipotético entre el paso solar y los ritos de paso

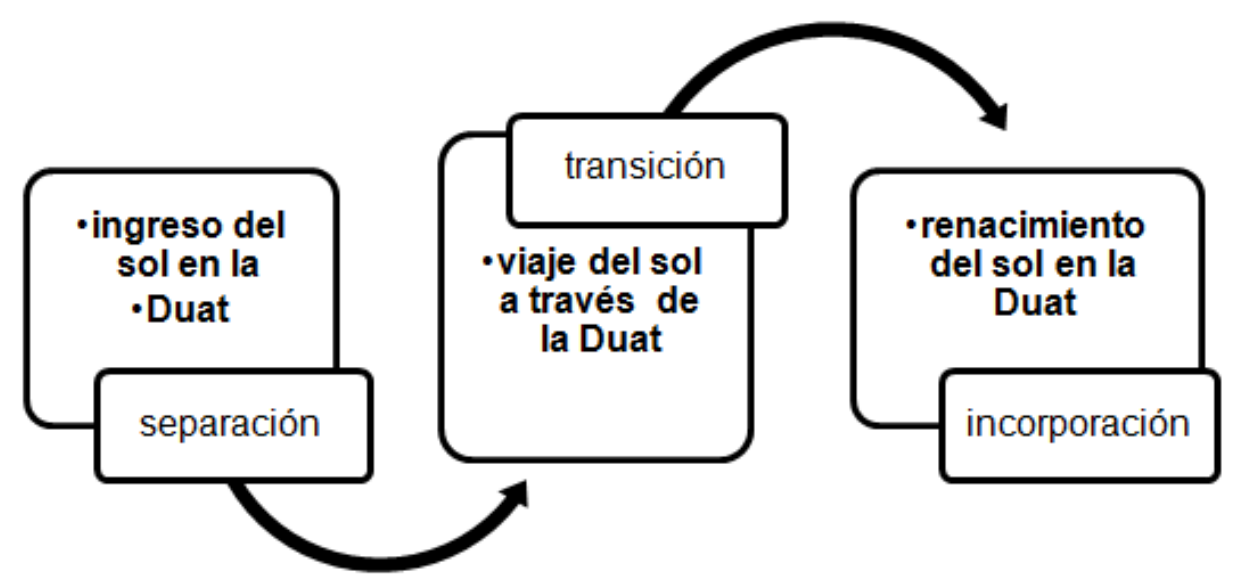

El ingreso de Ra en la Duat desencadena una serie de movimientos que se resuelven a partir de su presencia y que convergen en la perpetuación de su ciclo. Éste, con la regeneración como su consecuencia más visible, se compone de una infinidad de actos ejecutados por cada uno de los habitantes de la Duat. La repetición de tales actos, insoslayables para conservar la estabilidad universal, son los que precisamente creo que constituyen su fenomenología. En el caso de la regeneración solar, la perfectibilidad se sujeta menos a una secuencia única y diferenciada que a la incorporación simultánea de los mecanismos que conforman los ritos de paso descriptos por Van Gennep. Vale decir que la impronta que cada uno de ellos (separación, transición, incorporación) ${ }^{3}$ genera en los receptores de los actos rituales deviene en una compleja fluidez que aúna en su complejidad las tres instancias anteriores en un juego interrelacional permanente.

TABLA 3

Esquema simplificado de los ritos de paso según Van Gennep

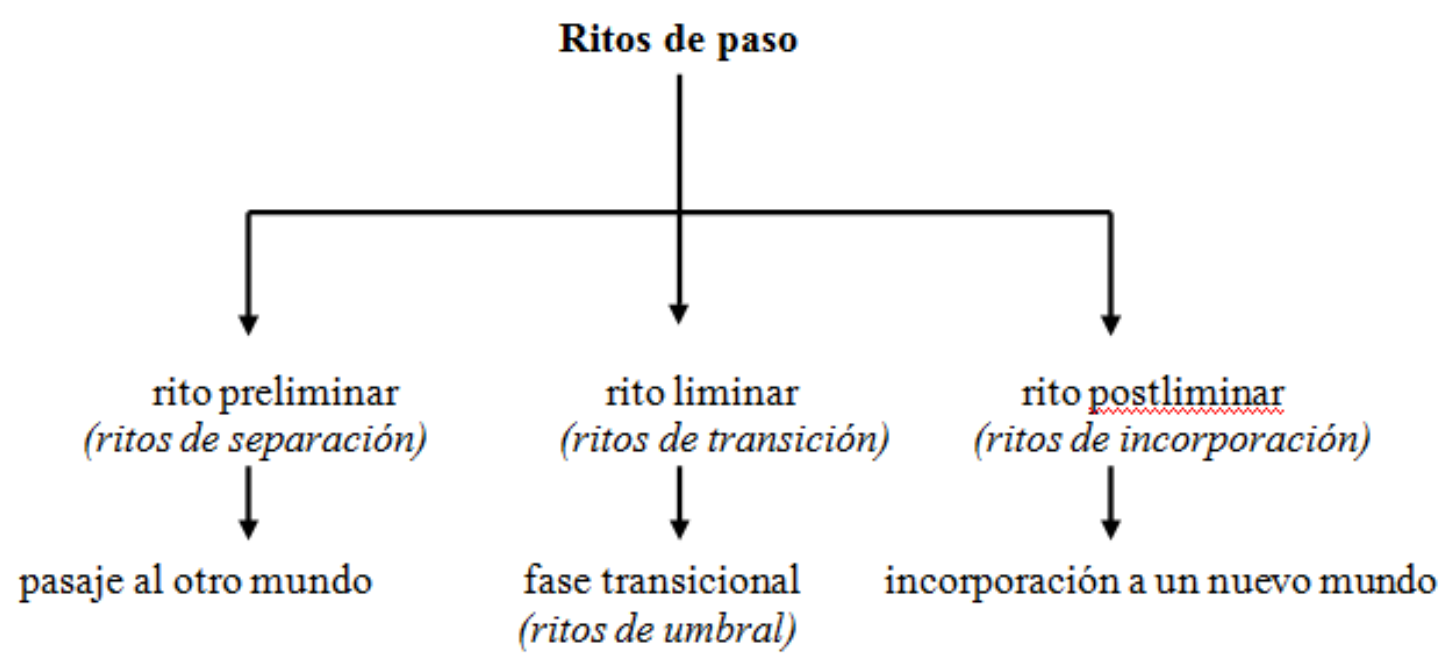

La noche es el móvil que objetiva y fundamenta el desencadenamiento diario del rito del paso solar por la Duat. De esta forma, la periodicidad del proceso concede al rito cósmico el carácter de automatismo propio de una transición trascendente. Y es este mecanismo inevitable como necesario el que determina la prescindencia 
de la acción humana. De la misma manera, el hiatus, entendido como el movimiento que media entre la potencia y el acto, se resuelve en la realidad de la noche que explica la transicionalidad entre los estados.

TABLA 4

Analogía entre el rito y los procesos en la Duat

\begin{tabular}{|c|}
\hline repetición........proyección inmutable de procesos \\
\hline $\begin{array}{l}\text { regularidad (ciclicidad) ... Ingreso disminuido-reconversion- } \\
\text { plenitud }\end{array}$ \\
\hline $\begin{array}{l}\text { retorno a lo prístino pre-determinado... perpetua vuelta al } \\
\text { orden primordial }\end{array}$ \\
\hline $\begin{array}{l}\text { eficacia... neutralizacion activa / provisorla del caos y nuevo } \\
\text { día con Ra regenerado }\end{array}$ \\
\hline reproducción inequívoca... recorrido periódico pre-fijado \\
\hline $\begin{array}{l}\text { Tesolucioli de ta opostcion... regenerados y comaentados } \\
\text { (diversidad v variedad) }\end{array}$ \\
\hline $\begin{array}{l}\text { superacion de escalas... progresion ascendente hasta el } \\
\text { amanecer }\end{array}$ \\
\hline automatismo... delimitación y discriminación por actividades \\
\hline
\end{tabular}

\section{Paratexto y activación en la Duat}

Dado que cualquier oscilación o desbalance en la composición ontológica que involucra a Ra y Osiris en la Duat dejaría intersticios por entre los cuales podría colarse el caos, la introducción del concepto general de sintaxis ritual deviene en herramienta de primer orden como reaseguro para evitar dicha situación.

El paratexto está en relación al texto al que pertenece, rodeándolo y extendiéndolo, precisamente para presentarlo, en el usual sentido del verbo, pero también en su sentido más fuerte: para hacerlo presente, para asegurar la presencia del texto en el mundo, su repetición y consumo (Genette, 1997:1), y está considerado dentro de un estructura (Genette, 1982:9). En el caso particular del índice del Libro del Amduat ello se cimenta en la interrelación entre el paratexto verbal (textos) y el paratexto icónico (imágenes) ${ }^{4}$.

Es esta complementariedad la que aquí se plantea como eje directriz entre un entorno simbólico y otro lingüístico, sintáctico. Es decir, constituye una posición intermedia entre el modelo "de iniciación" de Van Gennep y el de la sintaxis ritual de Staal.

Lo que Stall entiende como acción estereotipada sujeta a la exactitud del acto, recitación o canto (Staal, 1979:3), aquí se entiende como una relación de complementariedad entre el texto y la imagen, dada la polisemia de los rituales, y dado que éstos tienen una gran variedad de significados y funciones (Michaels, 2006:261).

En un entorno funerario pensado para uso real ${ }^{5}$ y localizado en su mayoría en las partes más recónditas de la tumba, tenemos el índice y una amplia serie de glosas o indicaciones (Nachschriften ${ }^{6}$ o Vermerke) que son fórmulas distribuidas a lo largo del texto ${ }^{7}$. El texto introductorio del Libro del Amduat es un ejemplo de paratexto en la forma de guía de conocimiento.

zS.w nj at jmnt aHaw bAw nTrw Swwt Axw jrw HAt wp jmnt sbA nj Axt jmnt pHwy kkw-zmAw sbA nj Axt jmnt ${ }^{8}$ rx bAw dwAtyw rx jrw rx sAxw.sn n raw rx bAw StAw rx jmyt wnwt nTrw.sn rx Dwjw.f n.sn rx sbAw wAwt appT nTr aA Hr.sn rx Smwt wnwt nTrw.sn rx wASyw Htmyw 
"Escritos para salir al Imentet, donde están los bAw, los dioses, las sombras, los Axw y lo que está hecho el comienzo de la cima del Imentet, la puerta de horizonte occidental que es el limite final de la oscuridad. Conocer los bAw de la Duat, conocer lo que está hecho, conocer las transfiguraciones de Ra, conocer los bAw secretos, conocer lo que está en las horas y sus dioses, conocer que él los llama, y los caminos en los que el gran dios pasa, conocer el paso de las horas y sus dioses, conocer lo prosperado y lo aniquilado".

Estas indicaciones paratextuales son las que dan sentido al texto por cuanto los modos de conocer, utilizar, accionar (y su complemento de ofrendar), lo significan y re-significan, objetivándolo. Estos paratextos ${ }^{10}$, en la forma de índices y glosas en el caso particular del Libro del Amduat, configuran su Sitz im Leben en la medida en que le confieren un sentido específico de verdaderas guías de de acción para su utilización.

Es necesario marcar que si bien es cierto que el conocimiento del contenido del índice del Amduat -y el texto de cierre de la versión abreviada ${ }^{11}$ posibilitan al rey una vuelta a la vida en el espacio y en el tiempo, no por ello conocer significa iniciarse. Ello no invalida algún tipo de conocimiento por parte del rey del saber y del entendimiento de la Duat y sus miembros (Barta, 1985:33), y que estas diferentes imágenes y fuentes textuales sean igualmente esfuerzos del rey muerto con el "conocimiento" 12 .

Introducimos el término ortopraxis (orto, "correcta” y praxis, "acción") utilizado por Staal para explicar la sintaxis ritual y concluir que el ritual es una actividad que está gobernada por reglas explícitas (Staal, 1979:4). Sin entrar en los detalles de su controvertida teoría ${ }^{13}$, con la otropraxis no sólo se procura una estructura ritual sistematizada sino también se asegura la efectividad de esta actividad primaria sujeta a operaciones de "incrustación" (Staal, 1979:16-18 y 1990; Hays, 2013:175-189), "modificación" (Staal, 1979:18-19; Hays, 2013:175-189), "inserción" u "omisión”, los que, según Staal, producen variaciones en la sintaxis ritual. La riqueza de los rituales egipcios en general, así como las distintas variantes del Libro del Amduat en particular ${ }^{14}$, confieren a la sintaxis una importancia que complementa la significación simbólica que lo caracteriza.

TABLA 5

Interacción entre texto e imagen en el Libro del Amduat

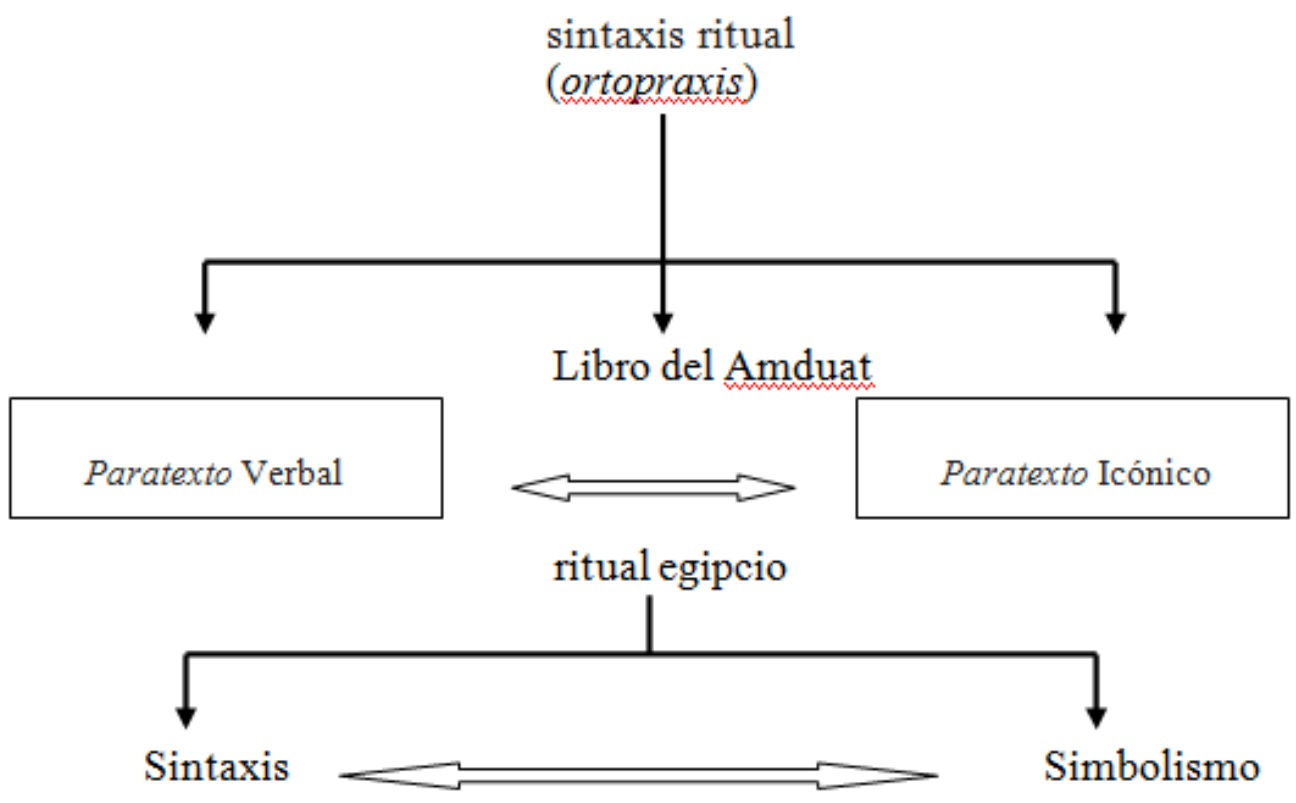


La propuesta procura hacer una analogía entre esta sintaxis ritual y los paratextos (icónicos y verbales) en el Libro del Amduat, a los efectos de complementar la hipótesis original de Hays respecto al modelo de Van Gennep y contextualizarlo a esta composición. La combinación de estas diferentes fórmulas -Nachschriften, Vermerke o Paratexto- se sujeta a la lógica de la estructura que para Staal define la sintaxis ritual. En la ordenación de estos paratextos verbales junto con los icónicos, se estatuye la funcionalidad del Libro del Amduat, no como una mera estructura de carácter mecánico en el sentido que Staal concede al rito, sino como resultado de la interacción entre la sintaxis y la semántica ritual ${ }^{15}$.

En estos textos que constituyen el rito del viaje solar por el cielo nocturno, el concepto de "liminalidad" se sujeta a la normatividad que rige el marco enunciativo de estos paratextos ${ }^{16}$. Ello significa que la etapa transicional -liminal- del difunto en el mundo de los muertos está menos subordinada al automatismo que supone el paso del mundo de los vivos al mundo de los muertos por la mera condición de "muerto", que a la correcta presencia y recepción del texto, paratexto, y su adecuada ortopraxis, como anteriormente vimos.

La siguiente selección de fórmulas ${ }^{17}$ - paratextos- del Libro del Amduat, parte de su funcionalidad en el conjunto textual. La disposición de estas estructuras paratextuales sigue una lógica que tiene una vinculación directa con el conocimiento de ciertos preceptos cuyo resultado es el desencadenamiento de la acción. Luego, y en medio de la actividad, el modo en que estos textos son utilizados - por la combinación de conocimiento y acción- es un reaseguro reforzado por las ofrendas concedidas.

\author{
FÓRMULAS DE CONOCIMIENTO (Wissenformel) \\ Amduat 1,2 Esto es hecho en la cámara secreta de la Duat, forma sagrada y oculta para \\ los pocos que la conocen. \\ Amduat 2,1 El que conozca sus nombres estará entre ellos (los dioses del registro) \\ Amduat 5, Int. El que conozca esto, su bA estará contento, y estará satisfecho \\ con las ofrendas de Sokar. Khemyt no cortará su cuerpo. \\ Amduat 7,3 El que conozca esto es uno cuyo bA no podrá tragar el cocodrilo. \\ Amduat 9, Int. El que conoce sus nombres sobre la tierra y conoce sus tronos en el Oeste. \\ Ocupará su trono en la Duat, estando entre los señores de la provisión y declarado \\ justificado por el tribunal en el día del juicio. Esto es útil para él sobre la tierra...
}

FÓRMULAS DE ACCIÓN(Handlungsformular)

Amduat 2,Int. Este Gran Dios le concederá campos en su lugar, entre los campos de Urnes. Él permanecerá con ellos, (su) bA irá en la comitiva de este Gran Dios, entrará en la tierra y desplegará los mechones de pelo de los dioses que llevan coletas. Atravesará el Comedor del Asno - amw aA-cuando se haya hecho la medición (?), comerá pan en la Barca de la Tierra, se le dará la cuerda delantera de la barca. Estas representaciones de los bAw de la Duat están hechas en pintura de esta forma secreta en la Duat.

Amduat 7, Int. Esto es útil en el cielo, en la tierra y sobre la tierra. El que conoce esto es un bA que está con Ra.

Amduat 7,2 Esta magia de Isis y el Mago más Antiguo es representada para repeler a Apofis de Ra en el Oeste, en el secreto de la Duat. Esto es realizado del mismo modo sobre la tierra. Quien lo realiza, está presente en la barca de Ra, en el cielo y en la tierra.

FÓRMULAS DE UTILIZACIÓN(Nützlichkeitformel)

Amduat 1,3 Lo que se ha hecho como esta imagen en el secreto de la Duat. El que hace estas imágenes es como el gran dios mismo. Es beneficioso para él sobre la tierra, un remedio verdadero, correspondiente a sus imágenes secretas que están pintadas.

Amduat 2,3 Eso es hecho como esta imagen secreta en el reino de la

Amduat 3,3 ...sin entrar al lugar de la destrucción -xtmj.t-. Él sale como una imagen en el dia, y respire aire a su hora.

Amduat 9, Int. Esto es hecho con sus nombres como esta imagen que está pintada sobre el lado este de la Cámara Oculta de la Duat. 
Amduat 10, Int. Esto está hecho como esta imagen que está pintada en el lado Este de la Cámara Oculta de la Duat.

FÓRMULAS DE OFRENDAS(Opferformel)

Amduat 2,1 Son hechas ofrendas sobre la tierra en sus nombres. Esto es eficiente para un hombre sobre la tierra, un remedio eficaz probado un millón de veces.

Amduat 6, Int. Todo lo que él (el difunto) desea le será ofrendado sobre la tierra.

Amduat 6, Int. Él será satisfecho con ofrendas a los dioses que están en el seguimiento de Osiris.

Esta sinopsis de las fórmulas paratextuales refleja ante todo una estructura de "mandatos", la cual conforma -junto con las exhortaciones y las expresiones imperativas muy comunes en el Libro del Amduat- la perlocutividad inherente de los textos performativos. En este sentido, la combinación de ritualidad y sintaxis explica la función de los textos sobre una visión simbólica y/o mítica; como señala Hays a propósito de los Textos de las Pirámides, lo que se refleja es una doctrina de la resurrección aplicada a cualquier rey para quien personaliza el conjunto de recitaciones con su nombre, y no un monarca ficticio o pseudo-histórico (Hays, 2012:8).

Esta conclusión es perfectamente adaptable para el Libro del Amduat, dado el origen real de la composición. Los paratextos y su consecuencia, la perlocutividad, supone una serie de procesos concurrentes y complementarios. En efecto, lo performativo es la consecuencia de la interrelación entre la locutividad, la ilocutividad y la perlocutividad.

TABLA 6

Procesos constitutivos de los paratextos

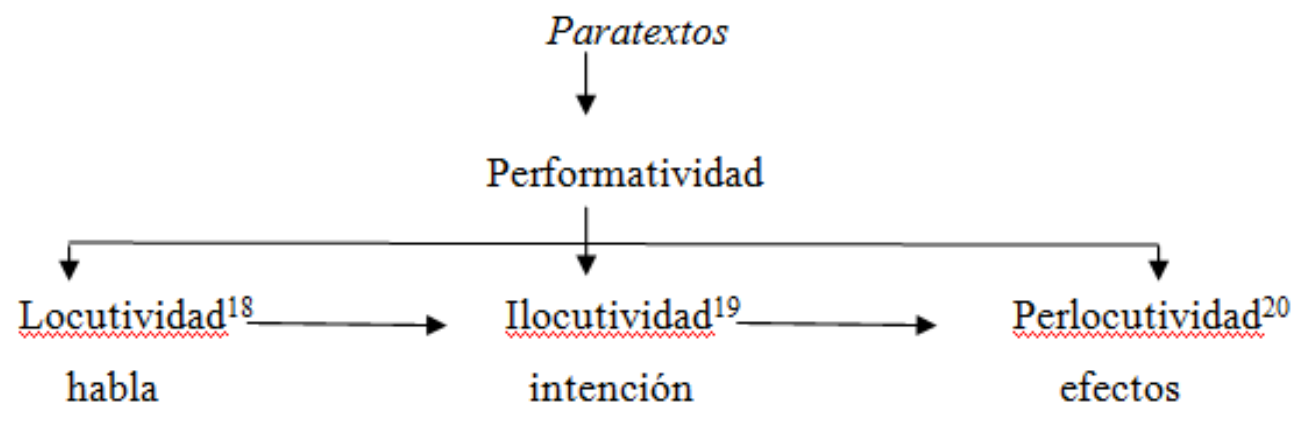

En este complejo proceso interactivo, y en orden de sucesión, cada una de los actos que conforman la performatividad es desencadenado por el anterior, conllevando lo que aquel activaba. El cuadro se explica, entonces, por un encadenamiento causa-efecto.

El Libro del Amduat conforma una estructura de relación en la que textos e imágenes constituyen una unidad y en la que los primeros hacen constantes referencias a las segundas (Hornung, 1999:32).

\section{Conclusiones}

La presencia de instrucciones paratextuales en el Libro del Amduat es un argumento que pone en duda la categoría de "liminalidad" como proceso gradual de incorporación o agregación experimentado por un iniciado, previo estado de incorporación y transición. En efecto, la presencia de los paratextos cambia el paradigma, al punto de plantear si la variedad de leyes, costumbres, convenciones y ceremoniales 
que constituyen la liminalidad y le dan sentido, conforman un simbolismo que en realidad opera a partir de unidades sintácticas. Estas pequeas unidades son denominadas ritos (d, p, a) y constituyen el ritual (D, P, A) según el análisis de Staal. En el siguiente gráfico puede verse como aquellos procesos "incrustación”, "modificación", "inserción" u "omisión" generan variaciones e interacciones en la estructura de la sintaxis ritual y en la interacción particular entre rito y ritual:

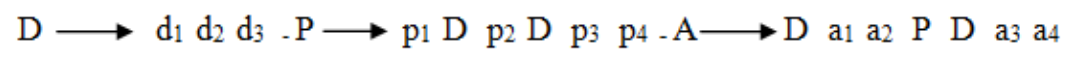

Esta alusión simplificada a los esquemas de Staal ${ }^{21}$ pretende mostrar cómo una estructura sintáctica puede oscilar entre varias combinaciones posibles. Intentamos expresar una analogía entre la variabilidad a que determinado ritual puede someterse a partir de las relaciones sintácticas, con la afectación de paratextos guías de acción- sobre una estructura cíclica mayor, como en el caso del pasaje solar por las horas de oscuridad. Comparado con esta "actividad" en la estructuración del ritual, el esquema de Van Gennep presume de estático, por cuanto el presunto iniciado se convierte en mero receptor de un diseño atávico y experimenta las vicisitudes de una transición inmutable (no en cuanto a contenido, sino en el sentido).

Separación, transición e incorporación no son compatibles con una estructura paratextual que, si bien cuenta con una base ritual, incorpora los paratextos con una fuerte carga de performatividad que complementa el carácter liminal del rito, cuando no lo invalida. En el caso estudiado, no se despoja al ritual del paso nocturno solar de su rico y variado significado, reduciendo su funcionalidad a un esquema sintáctico. La intención ha sido poner en consideración las conclusiones del modelo de van Gennep al confrontarlo con la sintaxis ritual, pero atendiendo a la carga simbólica (textual general para diferenciarla de lo paratextual, e icónica).

En este esquema, la identificación $\mathrm{Ra}$ /faraón conspira contra la realización de la secuencia separación, transición e incorporación por cuanto en el ingreso mismo en la Duat, Ra/ faraón "lleva a cabo sus transformaciones" (Libro del Amduat 1,2). Estos estadios en los que el faraón comienza a transformarse apenas comenzada la crisis nocturna, y en que los difuntos son aludidos inmediatamente como Axw -muertos transfigurados-, indican entonces que la sucesión supuesta en los pasajes se vea o evadida o, en el mejor de los casos, alterada. Si bien la separación puede mantenerse como punto de partida por la asunción del estado de "muerto", la transición y la incorporación se unifican en un único espacio transicional.

Es la conjunción de su carácter de guía de acción, de instrucciones sintácticas pero también semánticas, la que confiere al Libro del Amduat su condición de tratado "científico" o "cuasi-científico". Es esta condición tan particular la que pone en duda la aplicación del modelo de Van Gennep, por cuanto la ritualidad en sentido estricto se sujeta a un marco que la excede y da sentido. Ello significa que estas citas o anotaciones anexas al texto despojan al Libro del Amduat de su ritualidad, sin anularla pero sí condicionándola.

Concluyo con una nota final: que la estructura ritual tiene una significación que se sujeta a la carga semántica que inevitablemente tiene cualquier signo sintáctico, lo que significa que la fonología de la sintaxis conlleva por añadidura componentes semánticos o de significado. A la posibilidad de concebir "le rituel pour el rituel” (Michaels, 2006:247) así como la interpretación opuesta de una actitud omni-simbólica que afirma que es el simbolismo el que produce la sociedad ${ }^{22}$, lo proponemos es una postura que concilia el peso de la sintaxis con la carga simbólica de un ritual cósmico.

\section{REFERENCIAS}

Abt, Th. y Hornung, E. (2003). Knowledge for the Afterlife: the Egyptian Amduat -A quest for immortality. Zurich. Living Human Heritage Publications. 
Abt, Th. y Hornung, E. (2007). The Egyptian Amduat. The Book of the Hidden Chamber. Zurich, Living Human Heritage Publications.

Alston, W. (1974). Filosofia del Lenguaje. Madrid. Alianza Universidad.

Assmann, J. (1989). Death and initiation in the funerary religion of Ancient Egypt. En W. Kelly Simpson (ed.) Religion and Philosophy in Ancient Egypt, Yale Egyptological Studies 3:135-159.

Assmann, J. (1990). Die Macht der Bilder. Rahmenbedingungen Ikonischen Handelns im Alten Ägypten. En L. P. van Den Bosch; Hans G. Krippenberg; L. Leertouwer (eds.) Visible Religion. Annual For Religious Iconography, Volume VII. Genre in Visual Representations:1-20. Leiden. E. J. Brill.

Assmann, J. (1995). Egyptian Solar Religion New Kingdom. Re, Amun and the crisis of polytheism. New York. Kegan Paul.

Assmann, J. (2005). Death and Salvation in Ancient Egypt. Ithaca. Cornell University Press.

Baines, J. (1990). "Restricted Knowledge, Hierarchy, and Decorum: Modern Perceptions and Ancient Institutions", Journal of the American Research Center in Egypt 27:1-23.

Barta, W. (1985). Die Bedeutung der Pyramidentexte für den vestorbenen König. Münchener Ägyptologische Studien 39. Munich, Deutscher Kunstverlag.

Bonanno, M. (2015). La Duat como espacio de una dialéctica de la regeneración. Definiciones acerca del vinculo Ra-Osiris en los Textos del Amduat. In-habitación y re-significación del espacio funerario. $\mathrm{PhD}$ thesis, British Archeological Reports International Series 2738

Brunner, H. (1980). “Von Sinn der Unterweltsbücher”, Studien zur Altägyptischen Kultur 8: 79-84.

Budge, W. (1905). The Egyptians Heaven and Hell. Vol. 3. The Egyptian Heaven and Hell. London, Kegan Paul, Trench and Trübner and Co. Ltd.

Federn, W. (1960). "The Transformations in the Coffin Texts a New Approach", Journal of Near Eastern Studies 19 No 4: 241-257.

Genette, G. (1982). Palimpsestes. Paris. Èditions du Seuil.

Genette, G. (1997). Paratexts. Threeshold of Interpretation. Cambridge University Press.

Genette, G. (2001). Umbrales. Ed. Siglo XXI. México-Buenos Aires.

Grapow, H. (1936). "Studien zu den thebanischen Könnigsgräbern", Zeitschrift fur Ältagyptische Sprache und Altertumskunde 72: 12-39.

Hays, H. (2012). The Organization of the Pyramids Texts: Typology and Disposition. Probleme der Ägyptologie. Band 31. Leiden-Boston. E. J. Brill.

Hays, H. (2013). “The end of Rites of Passage and a start with Ritual Syntax in Ancient Egypt”. Rivista Studi Orientali Supplemento 2:165-186

Hegenbarth-Reichardt, I. (2009). Von Zeiten und Räumen. Oder: Wie unendlich ist die altägyptische Ewigkeit?. Zeit und Ewigkeit als Raum göttlichen Handelns. Berlin. Walter De Gruyter \& Co.: 3-28.

Hornung, E. (1967). Das Amduat. Die Schrift des verborgenen Raumes. Vol. 3. Die Kurzfassung. Nachträge. Wiesbaden, O. Harrassowitz.

Hornung, E. (1973). “Probleme der Wortforschung im Pfortenbuch”. Göttinger Miszellen 6:55-59.

Hornung, E. (1992). Idea into Image. Essays on Ancient Egyptians Thought. New York, Princeton University Press, Timken Publishers.

Hornung, E. (1999). The Ancient Egyptian Books of the Afterlife. Ithaca, Cornell University Press.

Jackendoff, R. (2002). Foundations of Language: Brain, Meaning, Grammar, Evolution. Oxford University Press.

Levi-Strauss, C. (1987). Introduction to the Work of Marcel Mauss. London, Routledge and Kegan Paul.

Manassa, C. (2007). The Late Egyptian Underworld: Sarcophagi and Related Texts from the Nectanebid Period. Wiesbaden, Ägypten und Altes Testament.

Manassa, C. (2013). "Divine Taxonomy in the Underworld Books". Archiv Für Religiongeschichte Volume 14, Issue $1: 47-68$. 
Michaels, A. (2006). Ritual and Meaning. En Theorizing Rituals: Issues, Topics, Approaches, Concepts. Jens Kreinath, Jan Snock and Michael Sausberg (eds.). Brill, Leiden, Boston.

Morenz, S. (1964). Gott und Mensch im alten Ägypten. Leipzig. Koehler \& Amelang.

Neureiter, S. (2005). “Schamanismus im Alten Ägypten”. Studien zur Altägyptischen Kultur 33:281-330.

Payne, R. K. (2002). "Ritual Syntax and Cognitive Theory”. En Pacific World: Journal of the Institute of Buddhist Studies, third series, no. 6:195-227.

Quirke, S. (1994). “Translating Ma'at”. Journal of Egyptian Archaeology 80:219-231.

Ries, J. (1989). Lo sagrado en la historia de la humanidad. Madrid. Ediciones Encuentro.

Seaquist, C.A. (2004). Ritual Syntax. PhD thesis, University of Pennsylvania, Philadelphia.

Schott, S. (1958). Die Schrift der verborgenen Kammer in Königsgräbern der 18. Dynastie. Nachrichten von der Akademie der Wissenschaften zu Göttingen 4.

Servajean, F. (2008). Les formules des transformations du Livre des Morts à la lumière d'une théorie de la performativité. XVIIIe-XXe dynasties. Bibliothèque $\mathrm{d}$ 'Etude 137. Institut français $\mathrm{d}$ 'archéologie orientale.

Staal, F. (1979). "The Meaninglessness of Ritual”. Numen 26: 2-22.

Staal, F. (1980). "Ritual Syntax. Sanskrit and Indian Studies”. Studies of Classical India Volume 2:119-142.

Staal, F. (1989). Rules without Meaning. Ritual, Mantras and the Human Sciences. New York-Bern-Frankfurt am Main-Paris, Peter Lang.

Van Gennep, A. (1960). The Rites of Passages. Chicago. The University of Chicago Press.

Turner, V. (1966). Liminality and Communitas. In The Ritual Process: Structure and Anti-Structure. Ithaca-New York, Cornell University Press.

Wente, E. (1982). “Mysticism in Pharaonic Egypt?”.Journal of Near Eastern Studies. 41 N³: 161-179.

Wiebach-Koepke, S. (2007). Sonnenlauf und Kosmiche Regeneration. Zur Systematik der Lebensprozesse in den Unterweltsbüchern. Wiesbaden. Harrassowitz.

Willems, H. (1996). The Coffin of Heqata (Cairo JdE 36418) A Case Study of Egyptian Funerary Culture of the Early Middle Kingdom. Leuven. Orientalia Lovaniensia Analecta 70.

Zeidler, J. (1999). Pforterbuchstudien. Teil I. Textkritik und Textgeschichte des Pfortenbuches. GOF IV, Reihe Ägypten 36. Wiesbaden. Harrassowitz.

\section{Notas}

1 "El Amduat es notable por la presencia de múltiples elementos paratextuales: un título, instrucciones para ser colocadas en un espacio tri-dimensional, y un "Catálogo." Los elementos paratextuales del Amduat apuntan hacia una aproximación egipcia al "texto" como una entidad que trasciende cualquier ejemplar particular y el Amduat representa uno de los ejemplos más claros de un "libro académico" en el registro textual egipcio" (Manassa, 2013: 68; NB: traducción del autor).

2 Stricto sensu, la zona recorrida por el sol durante la noche y espacio por excelencia de los difuntos.

3 Esto no invalida el hecho de interpenetraciones eventuales y/o una mayor agregación de una instancia sobre otra según el contexto lo requiera.

4 "El Amduat es el primer libro completamente ilustrado; los textos y las imágenes constituyen una unidad y el texto hace constantes referencias a las ilustraciones"; (Hornung, 1999:32; NB: Traducción del autor).

5 También los Libros del Más Allá fueron objeto de apropiación por particulares en el Tercer Período Intermedio (e incluso en la propia XX Dinastía con el papiro de Anhay y la tumba de Tjanefer, TT 158), (Quirke, 1994:225). Para la utilización de imágenes y motivos vinculados al recorrido diario solar y su renovación en papiros y tumbas privadas, ver Hornung (1992:317-323). Para la apropiación de los Libros del Más Allá del período de Nectanebo, ver Manassa (2007:437-468).

6 Ver Schott (1958, pp. 362-366) y Wente (1982:161-179).

7 Estás fórmulas se vinculan o principalmente con "fórmulas de conocimiento", (Wissenformel) "fórmulas de utilización” (Nützlichkeitformel) y fórmulas de acción” (Handlungsformular), Wiebach-Koepke (2007: 98-99). A ésta 
última se agrega una fórmula adaptada que la autora nombra como "fórmulas de ofrenda" (Opferformel), WiebachKoepke (2007:100).

8 HAt wpt nT jmnt pHwy kkw-zmAw, es la sinopsis del Libro del Amduat en su versión abreviada; (Hornung, 1967:1 y 28).

9 Título y Contenido del Libro del Amduat; (Abt y Hornung 2007:11-13)

10 "Como los ritos del Libro de los Muertos del Reino Nuevo en que las anotaciones paratextuales eran claras, eran prometidas en vida, leídas y entonces recitadas para así aprender lo que era necesario en un futuro escatológico: esto era una preparación para la muerte, aparentemente una garantía experimental de máxima liberación”, (Hays 2012:247; NB: Traducción del autor)

11

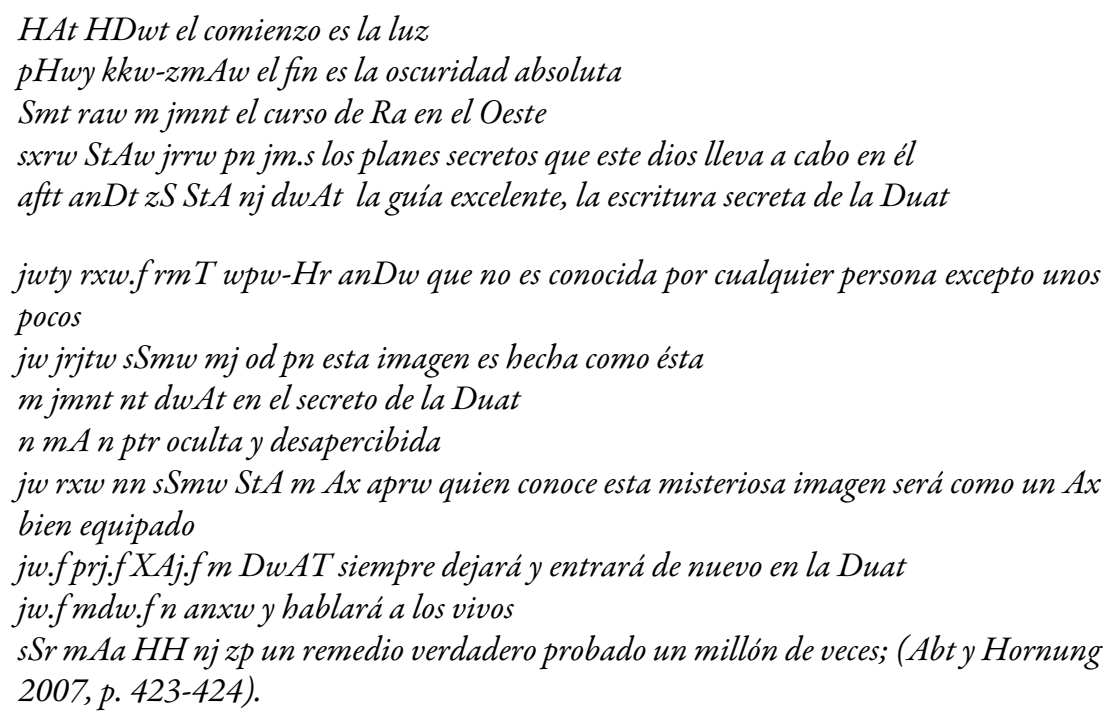

12 Para la problemática acerca de una presunta iniciación real en los misterios del sol, ver Budge (1905:80-81); Wente (1982:161-179); Hornung (1973:55-59); Baines (1990:1-23); Hornung (1999); Assmann (1995:Cap.1); Neureiter (2005:281-330); Assmann (2005:Cap.8); Assmann (1990:1-20); Willems (1996:279-282); Bonanno (2015:Cap. 5).

13 Para una detallada crítica de sus postulados, ver Michaels (2006:247-261). Para un estudio complementario de los postulados de Staal, véase Seaquist (2004).

14 Por ejemplo, la extensión del texto según la tumba o la existencia de una versión abreviada junto a la tradicional o larga.

15 "La sintaxis ritual pone el foco en los modos en que son realizadas las actividades en el curso de un ritual organizado, mientras la semántica ritual buscaría los significados de los agentes rituales, acciones, objetos, e implementos y relaciones entre ellos"; (Payne, 2002:212; NB: Traducción del autor). Para un análisis más detallado, ver Jackendoff (2002:2ss.).

16 "El solo hecho de la transcripción -y también de la transmisión oral- aporta a la idealidad del texto una parte de materialización gráfica o fónica, que puede inducir (...) efectos paratextuales”, Genette (2001:9; NB: Traducción del autor).

17 Las fórmulas paratextuales ascienden a 41. La selección obedece a una cuestión de espacio.

18 En el caso del Libro del Amduat, este acto podría ser prescindente.

19 Un acto ilocutivo tiene como base un acto locutivo y puede ser medio para un acto perlocutivo, pero no a la inversa, (Alston, 1974:61).

20 Un acto perlocutivo lleva consigo la producción de cierto efecto, (Alston, 1974:61).

21 Para la secuencia completa de la representación y explicación de la estructura ritual, ver Staal (1979:17-18).

22 Ver Levi-Strauss (1979:19-23). 